\title{
MRP1 but not MDR1 is associated with response to neoadjuvant chemotherapy in breast cancer patients
}

\author{
Mohsen Taheri ${ }^{\mathrm{a}, \mathrm{b}, \mathrm{c}, *}$ and Frouzandeh Mahjoubi ${ }^{\mathrm{a}}$ \\ ${ }^{a}$ Division of Medical Biotechnology, National Institute of Genetic Engineering and Biotechnology (NIGEB), \\ Tehran, Iran \\ ${ }^{\mathrm{b}}$ Genetics of Non-communicable Diseases Research Center, Zahedan University of Medical Sciences, Zahedan, \\ Iran \\ ${ }^{c}$ Department of Genetics, School of Medicine, Zahedan University of Medical Sciences, Zahedan, Iran
}

\begin{abstract}
A major problem in the treatment of breast cancer is the development of resistance to chemotherapeutic agents. Although the role of multidrug resistance 1 (MDR1) and multidrug resistance associated protein 1 (MRP1) in inducing drug resistance in many cancers has been widely investigated the clinical significance of expression of these genes in breast cancer remains unclear and the data is still controversial. We investigated the expression of MDR1 and MRP1 in breast cancer patients as well as the possible correlation between MDR1 and MRP1 and clinical response to chemotherapy. In the present study, MDR1 and MRP1 gene expression were investigated by real time reverse transcription polymerase chain reaction (RT-PCR) assay in 54 breast cancer tumors and in corresponding adjacent normal tissues before neoadjuvant chemotherapy. The expression level of MDR1 and MRP1 were significantly higher in breast tumors than normal breast tissues. Although a significant relationship was found between the MRP1 expression and response to treatment no association was observed between MDR1 expression and response to treatment. MDR1 and MRP1 expression levels have been shown to be independent of tumor size, histological grade and the status of progesterone or estrogen receptor.
\end{abstract}

Keywords: Multidrug resistance, real time PCR, breast cancer, MDR1, MRP1

\section{Introduction}

Resistance to chemotherapy limits the effectiveness of anti neoplastic treatments. In multi drug resistance (MDR) tumors become insensitive to many drugs with different structures and functions [1]. Even though breast cancer is one of the sensitive tumors to chemotherapy many of them become multidrug resistance [2].

${ }^{*}$ Corresponding author: Frouzandeh Mahjoubi, Division of Medical Biotechnology, National Institute of Genetic Engineering and Biotechnology (NIGEB) Pajoohesh Blvd. Tehran-Karaj Highway, 17th Km, Tehran, Iran. Tel.: +98 21 44580389; Fax: +98 21 44580399; E-mail: frouz@nigeb.ac.ir.
Neoadjuvant chemotherapy is an approach in the management of locally advanced breast cancer. It gives benefit in the operable breast cancers by increasing the chances of breast conservation. Neoadjuvant chemotherapy followed by surgery allows for assessment of the histopathologic response. Only about $70 \%$ of patients demonstrate a clinical response and merely 3\%-27\% achieve a complete histopathologic response (3). Therefore, roughly $30 \%$ of the patients received neoadjuvant chemotherapy are no responsive to this treatment and suffer from the side effects. The patients achieving a complete pathologic response after neoadjuvant chemotherapy have significantly longer disease-free overall and overall survival than nonresponders (3). Thus in any clinical practice it would be very important and beneficial for each patient 
if the patient could be informed in advance about the chance of being responsive or resistance to the neoadjuvant therapy.

One of the mechanisms inducing drug resistance is the efflux of drugs out of cells by increasing the activity of efflux pumps such as ATP Binding Cassette transporters (ABC transporters) [4]. ABC transporters are a family of transmembrane proteins with the ability to transport wide range of substrate molecules across cellular membranes [5].

MDR1 protein or P-gp is a transmembrane glycoprotein with molecular weight of $170 \mathrm{kDa}$, encodes by MDR gene [6]. It transports many hydrophobic substrates and anti-cancer drugs including etoposide, doxorubicin and Vinblastine [6,7]. The MDR1 gene with 28 exons and $1.2 \mathrm{~kb}$ is located on chromosome $7 \mathrm{q} 21.12$ [5].

Like p-gp, MRP is a member of ABC transporter that transport a wide variety of substrates, such as organic anion, leukotriene $\mathrm{C} 4$ as well as a number of chemotherapeutic agents, including doxorubicin, daunorubicin, vincristine and colchicines. Also it transports glutathione conjugates and cyclic nucleotides [8].

Although the role of MDR1 and MRP1 in inducing drug resistance in many cancers has been widely investigated the data is still controversial $(2,9,10,11)$. Therefore, the aim of the present study was to analyze the expression of MDR1 and MRP1 in breast cancer patients to see whether or not the expression of either of these genes or in combination or could be used as a marker to predict of drug sensitivity.

\section{Material and methods}

\subsection{Patients}

The project was approved by the local ethics committee of National Institute for Genetic Engineering and Biotechnology (NIGEB) and written informed consent was obtained from each case. Fifty four patients with locally advanced breast cancer admitted to Imam Khomeini Hospital in Tehran were enrolled in this study. The breast cancer patients had not yet received any chemotherapy treatment.

The tumor size and the axillary lymph node status were measured clinically and by using ultrasonography. At this stage, fresh tissue specimens (tumor and normal tissue adjacent to tumor) were collected by the clinicians in separated sterile tubes. Tissue samples were frozen and stored at $-70^{\circ} \mathrm{C}$.
The patients were then received three cycles of anthracycline based chemotherapy (FAC/FEC) regime at three weekly intervals.

Routine and metastatic work up was done including complete blood examination (total blood count, platelet count), chest radiograph, ECG (Echocardiography when ECG had a positive finding), liver function tests, Bone Scan.

The patients were assessed both clinically and by untrasonography for response in the form of reduction in breast tumor size and axillary lymph node status according to UICC criteria [12].

Complete response and partial response were considered when the tumor disappeared completely and when more than half of the tumor diameters showed regression with no local progression respectively. No response was considered for the patients whose tumor diameters had less than $50 \%$ regression.

\subsection{RNA extraction and cDNA synthesis}

After histologic diagnosis was confirmed for all samples (and thus cancer tissues could be distinguished from normal tissues) RNA was isolated from $100 \mathrm{mg}$ tissue using Tripure Isolation Reagent (Roche Applied Sciences, Indianapolis, USA). For cDNA synthesis, $1 \mu \mathrm{g}$ of total RNA from each sample was used to synthesize first-strand cDNA according to the manufacturer's protocol (Frementas,Mannheim, Germany).

\subsection{Real-time RT-PCR}

mRNA expression of the MDR1 and MRP1 gene was quantified as described and validated previously [13] by real-time RT-PCR using a lightcycler ${ }^{\mathrm{TM}}$ system (Roche Applied Sciences, Indianapolis, USA.) with Fast-Start DNA Master SYBR-Green I kit (Roche Applied Sciences, Indianapolis, USA.) using $\beta$-actin as housekeeping gene.

The PCR was performed in $20 \mu \mathrm{L}$ of solution, consisting of $2 \mu \mathrm{L}$ of Fast Start Master solution and $0.6 \mu \mathrm{M}$ of each primer. A total of $18 \mu \mathrm{L}$ of this reaction mix was placed into glass capillaries, and $2 \mu \mathrm{L}$ of cDNA was added as template.

A standard Lightcycler PCR program was established for each gene. Thermal Cycling were as follows: $95^{\circ} \mathrm{C}$ for $10 \mathrm{sec}$ followed by an amplification program 55 cycles with temperature ramp rate of $20^{\circ} \mathrm{C} / \mathrm{sec}$. The amplification program was $95^{\circ} \mathrm{C}$ for $10 \mathrm{sec}$, primer $T_{m}$ (Table 1) for $15 \mathrm{sec}$ and $72^{\circ} \mathrm{C}$ for $15 \mathrm{sec}$ with a single fluorescence acquisition at the end of the elon- 
Table 1

Sequences of primers

\begin{tabular}{lcll}
\hline Primer & $\begin{array}{c}\text { Amplicon } \\
\text { size }\end{array}$ & Sequence & $T_{m}$ \\
\hline MRP1-Forward & 294 bp & 5'-CGG AAA CCA TCC & $64^{\circ}$ \\
& & ACG ACC CTA ATC-3' & \\
MRP1-Reversed & & 5'-ACC TCC TCA TTC & \\
& & GCA TCC ACC TGG-3' & \\
MDR1-Forward & 308 bp & 5' TGA CAT TTA TTC & $62^{\circ}$ \\
& & AAA GTT AAA AGC 3' & \\
MDR1-Reversed & & 5' TAG ACA CTT TAT & \\
& & GCA AAC ATT TCA A3' & \\
$\beta$-actin-Forward & 161 bp & 5'-GAG ACC TTC AAC & $60^{\circ}$ \\
& & ACC CCA GCC-3' & \\
$\beta$-actin-Reversed & & 5'-AGA CGC AGG ATG & \\
& & GCA TGG G-3' & \\
\hline
\end{tabular}

Table 2

Comparison between tumor size and response to chemotherapy

\begin{tabular}{|c|c|c|c|c|c|c|c|c|}
\hline \multicolumn{9}{|c|}{ Tumor size } \\
\hline & \multicolumn{2}{|c|}{$<5 \mathrm{~cm}$} & \multicolumn{2}{|c|}{$5-8 \mathrm{~cm}$} & \multicolumn{2}{|c|}{$8-10 \mathrm{~cm}$} & \multicolumn{2}{|c|}{$>10 \mathrm{~cm}$} \\
\hline & $\mathrm{N}$ & $\%$ & $\mathrm{~N}$ & $\%$ & $\mathrm{~N}$ & $\%$ & $\mathrm{~N}$ & $\%$ \\
\hline Responder & 21 & 38.9 & 8 & 14.8 & 5 & 9.3 & 6 & 11.1 \\
\hline Non responder & 6 & 11.1 & 5 & 9.3 & 1 & 1.8 & 2 & 3.7 \\
\hline
\end{tabular}

gation step. The third segment consisted of a melting curve program at $95^{\circ} \mathrm{C}$ for $0 \mathrm{sec}, 70^{\circ} \mathrm{C}$ for $10 \mathrm{sec}$ and $95^{\circ} \mathrm{C}$ for $0 \mathrm{sec}$ with a liner temperature transition rate of $0.1^{\circ} \mathrm{C} / \mathrm{sec}$ with continuous fluorescence acquisition. Finally, a cooling program cooled the reaction mixture to $40^{\circ} \mathrm{C}$. To ascertain that fluorescence signals were associated with specific products, melting curves were constructed for each reaction, and the PCR products were electrophoresed on $1.5 \%$ agarose gel.

\subsection{Data analysis}

The raw data were analyzed using version 3.03 of the Lightcycler software as described. previously [13] The software calculates the relative amount of the target gene and the reference gene (housekeeping gene) based on the crossing point which was defined as the cycle number at which the fitted line in the log-linear portion of the plot intersected the threshold level. An external standard curve for MDR1 and $\beta$-actin was generated from a serial dilution of mRNA of each gene. For each sample, the amounts of MDR1 and the housekeeping gene were measured. Finally, the relative expression was calculated as the ratio of MDR1 to $\beta$-actin in each sample. Statistical analysis was performed using SPSS for software V16.0 (SPSS, Inc., Chicago, IL). Differences between groups were analyzed by one-way analysis of variance (ANOVA) and Tukey's multiple comparison tests. Spearman correla-
Table 3

Comparison between histological grade and response to chemotherapy

\begin{tabular}{|c|c|c|c|c|c|c|}
\hline \multicolumn{7}{|c|}{ Histological grade } \\
\hline & \multicolumn{2}{|c|}{ Stage I } & \multicolumn{2}{|c|}{ Stage II } & \multicolumn{2}{|c|}{ Stage III } \\
\hline & $\mathrm{N}$ & $\%$ & $\mathrm{~N}$ & $\%$ & $\mathrm{~N}$ & $\%$ \\
\hline Responder & 6 & 11.1 & 22 & 40.7 & 12 & 22.2 \\
\hline Non responder & 3 & 5.6 & 8 & 14.8 & 3 & 5.6 \\
\hline
\end{tabular}

tion coefficient was used to determine the relationship between expression levels of MRP1 and LRP. Association between clinical characteristics and an expression level was determined using Chi-squared test. A $P$ value less than 0.05 was considered statistically significant.

\section{Results}

\subsection{Patients' clinical and pathological data}

In total 54 breast cancer patients were studied (all female). The medium age of the patients was 47.26 year (SD 13.89). Invasive ductal carcinoma and invasive lobular carcinoma were diagnosed in $85 \%$ and $11 \%$ of the patients respectively. Thirty two patients $(59 \%)$ were diagnosed at postmenopause and $22(41 \%)$ at premenopause status. Grade I, II, and III were diagnosed by pathology examination in $17 \%, 55 \%$ and $28 \%$ of the patients respectively. Fifty percentage of the patients had tumor size smaller than $5 \mathrm{~cm}(n=27)$, about $35 \%$ $(n=19)$ of the patients had tumor size between 5âĂŞ8 cm, while $15 \%$ of the patients had tumors size larger than $10 \mathrm{~cm}(n=8)$. Thirty four $(63 \%)$ of the patients had lymph node metastasis. Estrogen and progesterone receptors positive were seen in $69 \%$ and $62 \%$ of the patients respectively.

The patients were divided into two groups according to the results of the neoadjuvant therapy; patients classified as having partial response formed the positive response group, while patients classified as showing no response made up the negative chemotherapy response group.

Forty patients had partial response $(75 \%)$ and fourteen had no response $(25 \%)$. There was no patient with complete response.

\subsection{Association between clinicopatholgy markers and response to chemotherapy}

We investigated whether or not traditional clinical prognostic factors as stage of tumor, tumor size and 

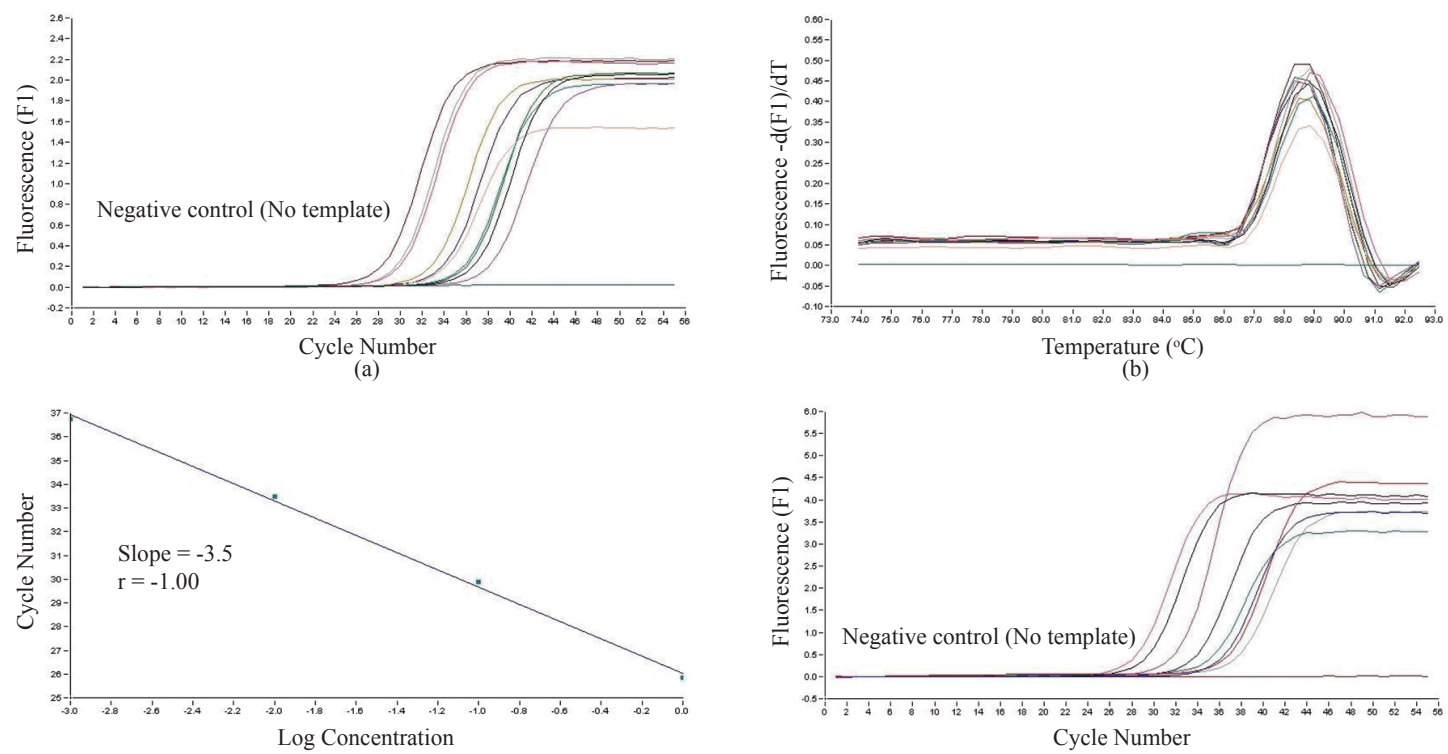

(d)

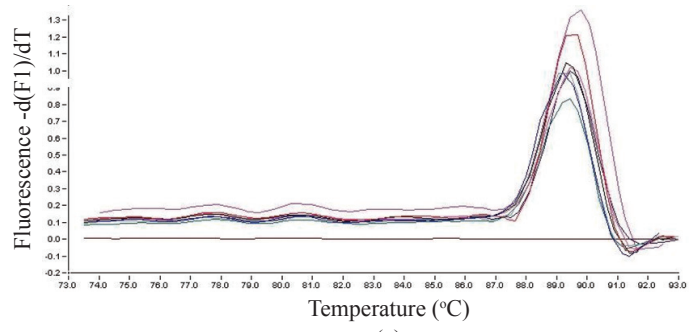

(e)

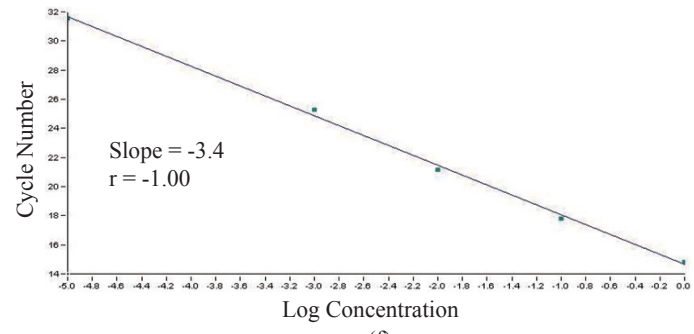

(f)

Fig. 1. Real-time RT-PCR for quantification of MRP1 (1a-1c) and $\beta$-actin (1d-1e) mRNA with amplification curves (1a,1d) and melting point analysis (1b,1e). Standard curves (1c, 1f) were generated by plotting the Ct value vs. the log of the dilution of the calibrator cDNA. (Colours are visible in the online version of the article; http://dx.doi.org/10.3233/DMA-130985)

lymph node involvement could be predictor of response to chemotherapy. There was no relationship between tumor size (Table 1), histological grade (Table 2) and lymph node involvement with response to drug ( $P=0.823, P=0.069$, and $P=0.06$ respectively).

\subsection{Real-time PCR validation}

For the mRNA expression of the target genes and the housekeeping gene a reliable and reproducible relative quantification method based on LightCycler ${ }^{\mathrm{TM}}$ technology was established and validated. Melting curve analysis showed only one peak for each reaction and this also confirmed by electrophoresis of PCR products that showed only one band of the expected size.

For high PCR efficiency the slope of the calibration curve approach was 3.402 (optimum curve slope) and the $\mathrm{y}$-intercepts close to the $\mathrm{Ct}$ value of the negative control. The amplification curves, melting curve analy- sis, and standard curves are exemplified for MRP1 and $\beta$-actin in Fig. 1.

\subsection{Expression of MDRI and MRPI in normal and tumoral breast tissue}

The expression levels of MDR1 and MRP1 in normal and tumoral tissues of the patients are shown in Fig. 2. Mean expression level of MDR1 in normal breast tissues were $0.7221 \pm 0.1098$ and in tumoral breast tissues were $0.7859 \pm 0.1108$. A statistically significant increase in MDR1 expression was observed when samples from normal breast tissue were compared with tumoral breast tissue (Fig. 2). The expression level of MRP1 in normal and tumor tissues were $0.7560 \pm 0.13348$ and $0.8709 \pm 0.11724$, respectively. As shown in Fig. 2, the expression level of MRP1 was significantly higher in breast tumor than normal breast tissue $(P=0.0001)$. Subsequent analysis with regard 


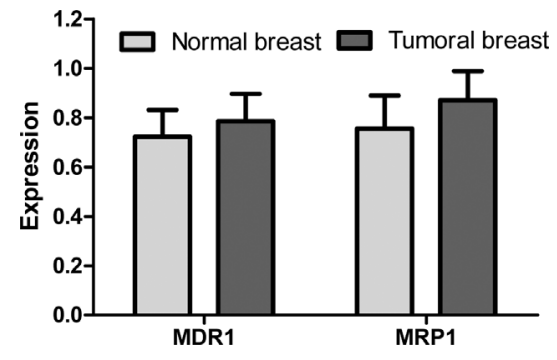

Fig. 2. Mean expression level of MDR1 and MRP1 in normal and tumoral breast tissue.

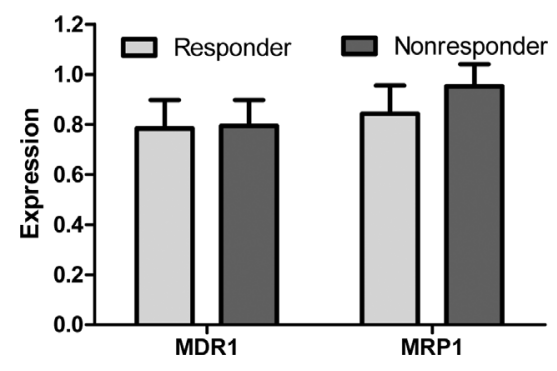

Fig. 3. Mean expression level of MDR1 and MRP1 in responder and non-responder.

to potential interrelationships of these drug resistance genes revealed that the mRNA levels of MDR1 were not related to MRP1 $(P>0.05)$.

\subsection{Correlation between $m R N A$ expression of $M D R 1$ and MRPI and response to chemotherapy}

A comparison between the tumors of responder versus nonresponder patients with respect to the relative expression levels of MRP1 showed that the expression level of MRP1 was significantly higher in nonresponder than responder patients $(P<0.05)$. Mean expression level of MRP1 in responder and nonresponder were $0.8422 \pm 0.11331$ and $0.9529 \pm 0.08809$. While the mean expression level of MDR1 in responder and nonresponder were $0.7832 \pm 0.1144$ and $0.7936 \pm$ 0.1035 , respectively (Fig. 3). Although this value was higher in nonresponder this difference was not statistically significant.

\section{Discussion}

Breast cancer with 1 million new cases in every year is the most common malignancy in women [14]. Despite the advances in therapeutic methods about $40-50 \%$ of patients will eventually die from the disease [14]. Therefore researchers are looking for appro- priate therapeutic methods in order to increase the survival rate. This is facilitated by finding suitable markers which might predict clinical outcome (prognostic markers) and response to a particular type of therapy (predictive markers).

The development of multidrug resistance is a major obstacle to successful chemotherapy in cancers. Various mechanisms, such as reduced drug uptake, the efflux of intracellular drugs, the activation of DNA repair pathways, and the induction of anti-apoptotic machineries can confer multidrug resistance in cancer cells [6]. Despite the intensive studies regarding the role of these genes in inducing drug resistance in cancer patients the data is still controversial and debated. A possible role of the MDR1 and MRP1 in clinical breast cancer has previously been studied but the results are not conclusive $[2,9,11,15]$.

In the present study we examined the expression of these two genes in breast cancer patients by real time RT PCR. We examined whether the expression of either or combination of these two genes in breast cancer tumor cells correlates with response to neoadjovant chemotherapy.

The expression levels of MDR1 and MRP1 was found to be significantly different between tumoral tissues and normal breast tissues. MDR1 and MRP1 are apparently expressed at higher levels in carcinoma cells than non-cancer cells. However, we found no significant correlation between MDR1 expression and response to treatment. Arnal and co workers (2000) demonstrated comparatively to normal tissues, a significant induction of MDR1 expression in untreated tumors but after treatment no differences were detected between tumor and normal samples. Also no significant relationship was found between MDR1 expression and clinical response to chemotherapy neither before nor after treatment [15].

Faneyte et al. [16] compared the post-chemotherapy expression of MDR1 in tumors that had microscopic evidence of response with that did not respond. The difference was not statistically significant. In prechemotherapy samples, responders did not differ significantly from non-responders. They found no correlation between clinical response and MDR1 expression [16]. This is similar to finding of Rudas et al. [9] that in a study on 80 patients with locally advanced breast cancer demonstrated that the expression of MRP1, and MDR1 increase after preoperative chemotherapy but there was no association between their expression and response to chemotherapy [9]. In contrast to these studies Burger et al. [2] reported a 
significant correlation between MDR1 gene expression and response to chemotherapy. MDR1 gene expression occurred in $68 \%$ of resistant patients, but in only $17 \%$ of clinically responsive patients [2]. Similar to this Atalay et al. [17] showed a strong correlation between MDR1 expression and response to treatment. While the expression rate of MDR 1 was $100 \%$ in clinically resistant patients only $5 \%$ of the clinically responsive patients had MDR1 gene expression [17].

We found a significant positive correlation between MRP1 expression and response to treatment. Nooter et al. [18] evaluated the role of MRP1 expression in the prognosis and response to chemotherapy of breast cancer patients. They showed the presence of MRP1 protein was associated with lower response rate in previously untreated patients who received first-line chemotherapy [18]. Similarly Filipits and co workers [11] suggested that MRP1 expression plays an important role in the clinical resistance to adjuvant $\mathrm{CMF}$ chemotherapy [11].

In contrast to the above findings Burger et al. [2] showed an inverse relation between MRP1 gene expression and clinical response to chemotherapy but expression of this gene was not significantly different in clinically responsive and unresponsive patients [2]. Atalay et al. [17] showed that although $80 \%$ of the clinically unresponsive patients had higher MRP1 gene expression, but the relation between MRP1 expression and clinical drug response was not significant [17].

In regards to relationship between the expression level and clinicopathology markers such as stage of tumor, tumor size, hormone status and lymph node involvement there was no association between expression of these genes and clinicopathology markers. Further studies showed similar results $[2,10,19]$.

In conclusion, conflicting results have been obtained from several studies regarding the role of these genes in inducing MDR. This may be partly due to the methods applied for investigation of gene expression. For this reason it seems that a gold standard method should be presented in order to study the expression of these genes and their role in drug resistance. Hence we recommend Real time PCR as a good method for evaluation of these gene expressions at mRNA level because Real-time PCR is simple to use, and requires only minimal experience and skills. It is the method that allows quantification and provides maximum sensitivity (e.g. 10,000 times more sensitive than northern blot).

Furthermore, future prospective studies on large patient populations are required to further explore the impact of drug resistance genes on the clinical outcome of breast cancer patients treated with chemotherapy.

\section{Acknowledgements}

This project was supported by a NIGEB grant (No:412). The authors would like to thanks all patients who willingly participated in the study.

\section{References}

[1] Gottesman MM. Mechanisms of cancer drug resistance. Annu Rev Med 2002; 53: 615-627.

[2] Burger H, Foekens JA, Look MP, Meijer-van Gelder ME, Klijn JG et al. RNA expression of breast cancer resistance protein, lung resistance-related protein, multidrug resistanceassociated proteins 1 and 2 , and multidrug resistance gene 1 in breast cancer: correlation with chemotherapeutic response. Clin Cancer Res 2003; 9(2): 827-36.

[3] Chintamani, Singhal V, Singh JP, Lyall A, Saxena S, Bansal A. Is drug-induced toxicity a good predictor of response to neo-adjuvant chemotherapy in patients with breast cancer?-a prospective clinical study. BMC Cancer 2004; 13: 4-48.

[4] Kuo, MT. Roles of multidrug resistance genes in breast cancer chemoresistance. Adv Exp Med Biol 2007; 608: 23-30.

[5] Dean M. ABC Transporters, Drug Resistance, and Cancer Stem Cells. J Mammary Gland Biol Neoplasia 2009; 14: 3-9.

[6] Gottesman M, Fojo T, Bates SE. Multidrug resistance in cancer: role of ATP-dependent transporters. Nat Rev Cancer 2002; 2(1): 48-58.

[7] Van der Deen M, De Vries EG, Timens W, Scheper RJ, Timmer-Bosscha, H et al. ATP-binding cassette (ABC) transporters in normal and pathological lung. Respir Res 2005; 6: 59

[8] Cole SP, Bhardwaj G, Gerlach JH, Mackie JE, Grant CE et al. Overexpression of a transporter gene in a multidrug-resistant human lung cancer cell line. Science 1992; 258(5088): 16504.

[9] Rudas M, Filipits M, Taucher S, Stranzl T, Steger GG et al. Expression of MRP1, LRP and Pgp in breast carcinoma patients treated with preoperative chemotherapy. Breast Cancer Res Treat 2003; 81(2): 149-57.

[10] Larkin A, O’Driscoll L, Kennedy S, Purcell R, Moran E et al. Investigation of MRP-1 protein and MDR-1 P-glycoprotein expression in invasive breast cancer: a prognostic study. Int $\mathrm{J}$ Cance 2004; 112(2): 286-294

[11] Filipits M, Pohl G, Rudas M, Dietze O, Lax S et al. Clinical role of multidrug resistance protein 1 expression in chemotherapy resistance in early-stage breast cancer: the Austrian Breast and Colorectal Cancer Study Group. J Clin Oncol 2005; 23(6): 1161-8.

[12] Hayward JL, Carbon PP, Kumaoka S, Seagloff A, Rubens RD. Assessment of response to therapy in advanced breast cancer:A project of the Programme on Clinical Oncology of the International Union Against Cancer, Geneva, Switzerland. Cancer 1997; 39: 1289-1294.

[13] Golalipour M, Mahjoubi F, Sanati MH, Alimoghaddam K. Gene dosage is not responsible for the upregulation of MRP1 gene expression in adult leukemia patients. Arch Med Res 2007; 38(3): 297-304.

[14] McPherson K, Steel CM, Dixon JM. ABC of breast diseases. Breast cancer epidemiology, risk factors, and genetics. Bmj 2000; 321(7261): 624-8. 
[15] Arnal M, Franco N, Fargeot P, Riedinger JM, Brunet-Lecomte $\mathrm{P}$ et al. Enhancement of mdr1 gene expression in normal tissue adjacent to advanced breast cancer. Breast Cancer Res Treat. May 2000; 61(1): 13-20.

[16] Faneyte IF, Kristel PM, van de Vijver MJ. Determining MDR1/P-glycoprotein expression in breast cancer. Int J Cancer 2001; 93(1): 114-122.

[17] Atalay C, Deliloglu Gurhan I, Irkkan C, Gunduz U. Multidrug resistance in locally advanced breast cancer. Tumour
Biol 2006; 27(6): 309-18

[18] Nooter K, de la Riviere GB, Klijn J, Stoter G, Foekens J. Multidrug resistance protein in recurrent breast cancer. Lancet 1997; 349(9069): 1885-1886.

[19] Faneyte IF, Kristel PM, van de Vijver MJ. Multidrug resistance associated genes MRP1, MRP2 and MRP3 in primary and anthracycline exposed breast cancer. Anticancer Res 2004; 24(5A): 2931-2939. 


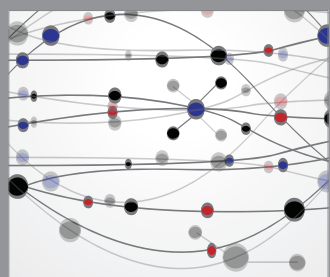

The Scientific World Journal
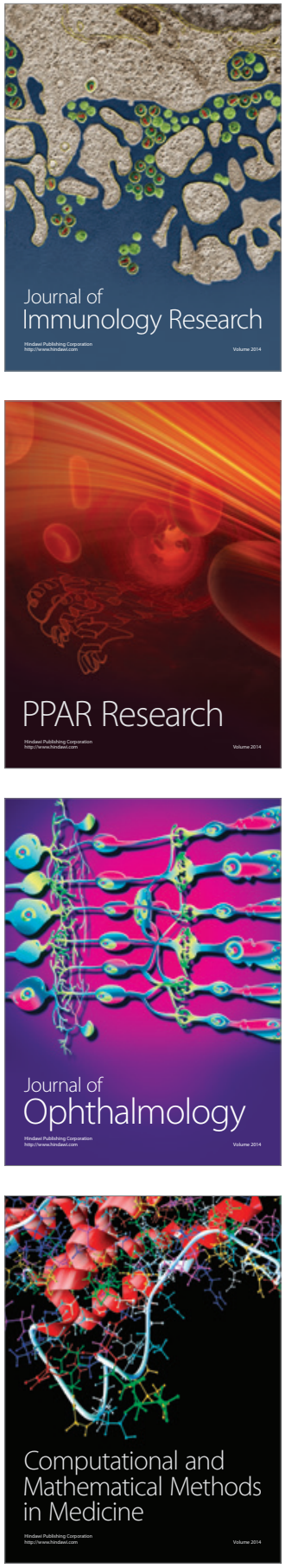

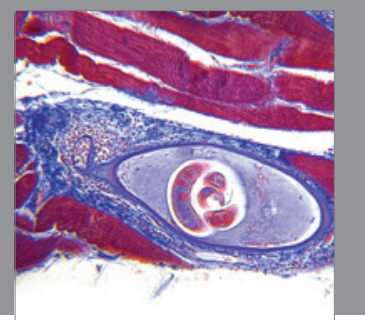

Gastroenterology

Research and Practice
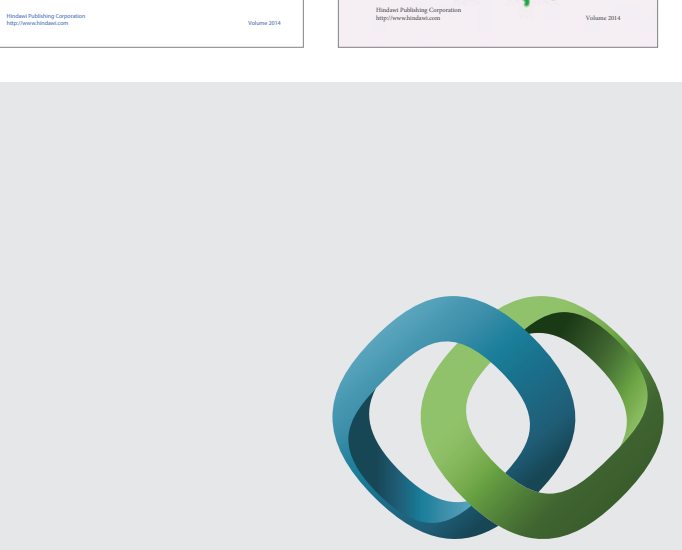

\section{Hindawi}

Submit your manuscripts at

http://www.hindawi.com
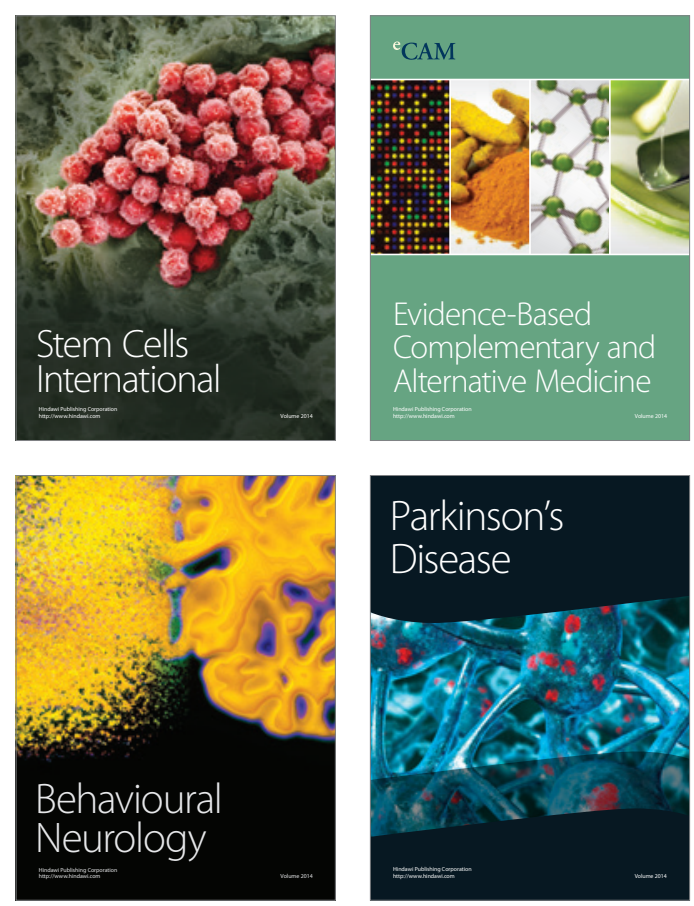

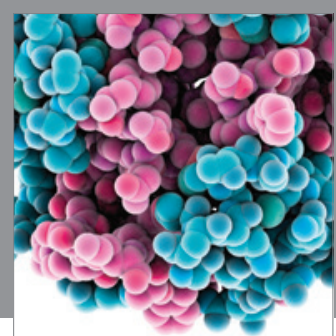

Journal of
Diabetes Research

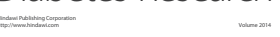

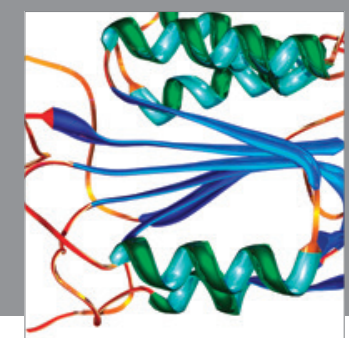

Disease Markers
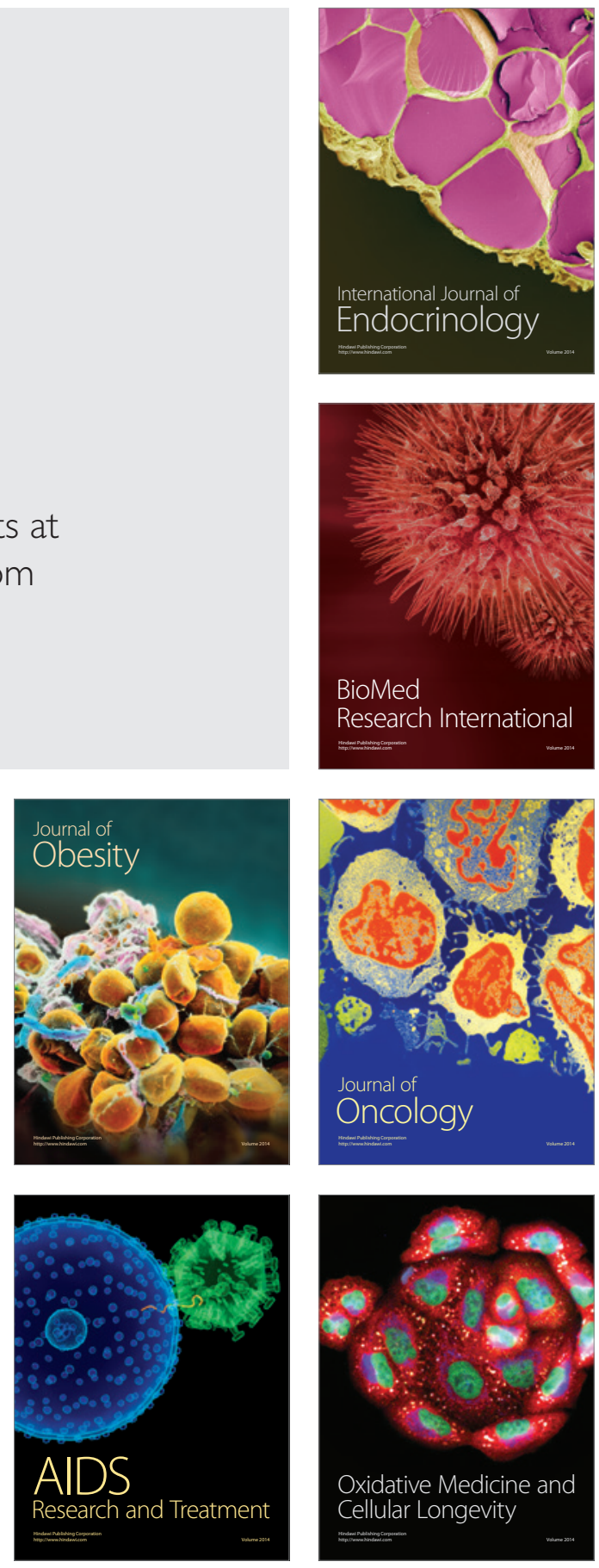